\title{
Quality of the Surface Texture and Mechanical Properties of FDM Printed Samples after Thermal and Chemical Treatment
}

\author{
Tomasz Kozior ${ }^{1}$ - Al Mamun ${ }^{2}$ - Marah Trabelsi2,3 - Lilia Sabantina ${ }^{2}$ - Andrea Ehrmann²,* \\ ${ }^{1}$ Kielce University of Technology, Faculty of Mechatronics and Mechanical Engineering, Poland \\ 2 Bielefeld University of Applied Sciences, Faculty of Engineering and Mathematics, Germany \\ ${ }^{3}$ National School of Engineers of Sfax, Tunisia
}

\begin{abstract}
Additive manufacturing technologies are nowadays used in various industries. In most cases, however, the surface texture of the produced models is unsatisfactory and requires further processing, aiming to reduce surface roughness and waviness. The quality of the surface layer in many cases plays not only an aesthetic role but also affects, for example, the process of wear and tribological properties. In the presented work, samples prepared by fused deposition modelling technology from polylactic acid (PLA) material were subjected to tests. The samples were subjected to heat or chemical treatment through the use of acetone. The quality of the surface texture was tested both before and after the treatments. In addition, tests were carried out to determine the effect of the presented finishing treatment on the tensile strength of the tested sample models. The test results showed that both thermal treatment and acetone treatment influence the surface texture quality, especially the waviness, and that the acetone treatment can improve some mechanical properties.
\end{abstract}

Keywords: 3D printing, finishing treatment, fused deposition modelling, surface texture, mechanical properties

Highlights

- The impact of finishing, thermal, and chemical treatment in the form of acetone on the quality of parameters of the surface texture was examined.

- $\quad$ Thermal treatment slightly improves surface roughness, but significantly reduces surface waviness parameters.

- $\quad$ Acetone in liquid form is much more efficient compared to its gas state.

- Acetone treatment affects the waviness parameters positively; however, reducing the tensile strength of the samples and increasing elongation at break.

\section{INTRODUCTION}

Modern additive manufacturing technologies allow for the production of models from plastics, ceramics and metals, thanks to a wide range of available materials ([1] and [2]). In addition, some of the materials used are characterized by such features as biocompatibility, high temperature and chemical resistance as well as good tribological properties [3]. An unquestionable advantage of three dimensional (3D) printing is the possibility of almost immediate building of models based on 3D digital models, on the basis of which the stereolithography (STL) model is created (approximated with triangles), enabling decentralized and personalized production [4]. Although currently there are about a dozen additive technologies based on polymer materials, (e.g., fused deposition modelling (FDM), stereolithography apparatus (SLA) or polyjet modelling (PJM), ceramic materials (freeze-form extrusion fabrication (FEF)) and metal material (selective laser sintering (SLS)), selective laser melting (SLM)), with FDM one of the earliest technologies has found the greatest application [3]. This technology allows the production of models using materials based on acrylonitrile butadiene styrene (ABS) or polylactic acid (PLA), even with additives such as carbon fibres ([5] to [7]). The significant advantage of FDM technology is the ability to build almost unlimited large models while maintaining low costs of material, machine purchase, and service. In addition, this technology is one of the few with which it is possible to manufacture objects on existing models. This makes the FDM technology widely used in both the prototyping and manufacturing of short production runs. Additive manufacturing technologies have found very wide applications in many industries, such as foundries ([8] and [9]), the food industry [10], the textile industry ([11] and [12]), the construction of technical seals ([13] and [14]), the aviation and automotive industries, etc.

FDM, with its simple model construction principle, is thus one of the most commonly used generative technologies. The materials for the models and the support are delivered to the printing heads in the form of thin rods with typical diameters of $1.75 \mathrm{~mm}$ or 2.85 to $3.0 \mathrm{~mm}$, where they are heated to a temperature slightly lower than the melting temperature of the material, and then spread on 
the platform in the place of the currently built layer (cross-section) of the model. After building the first layer, the building platform is lowered by a previously set value, and the next layer of material is distributed and combined with the previously created one [2]. With this technology, there are no additional catalyst connecting layers such as a binder or a laser beam; the layers are joined by the temperature of the extruded polymer.

The quality of the technological surface texture [15], mechanical properties ([16] and [17]) of the produced models and tribological wear in almost all additive technologies depend on appropriately selected technological parameters. However, only selected treatments are reported in the literature ([18] to [22]).

In [20], the authors tested cylindrical samples manufactured with FDM technology. The model material for samples was PLA, and acetone treatment was carried out by using a gas atmosphere. Several acetone exposure times were applied to the test samples in the range of 0 minutes to 10 minutes. Test results showed that as the acetone exposure time increased, the compressive strength of the samples increased slightly. In turn, roughness measurements showed that the roughness of the surfaces was clearly improved.

The analysis of the influence of finishing treatment in the use of acetone was also presented in [21]. The authors tested samples prepared in the fused deposition modelling technology from the materials ABS and PLA. Tensile strength measurements were made using a universal testing machine, the results of which showed that acetone vapour treatment for an undefined duration slightly reduces tensile strength, while improving surface roughness and polymer ductility.

Heat treatment of samples made in FDM technology and an analysis of its impact on mechanical properties was also presented in [22]. The authors made two types of samples for both bending flexural and tensile tests. The samples were then subjected to heat treatment and strength measurements, which showed that heat treatment allows for a slight increase in the strength of the samples tested.

In a recent study, we thus examined several FDM printed samples after thermal or chemical finishing treatment, reporting to the best of our knowledge for the first time on treating PLA with fluid acetone for different durations, and determined the influence of treatment on the quality of the surface texture (roughness and waviness) and selected mechanical properties.

\section{MATERIALS AND METHODS}

The test samples were manufactured in fused deposition modelling technology. The principle of model construction with the use of FDM technology is shown in Fig. 1. The test samples were designed using SolidWorks software (Dassault Systèmes SolidWorks Corp., Waltham, Massachusetts). Then CAD models were saved as STL files with a linear tolerance of $0.01 \mathrm{~mm}$ and an angle tolerance of 5 degrees. The file saved in this way consisted of 188 triangles, and its approximation is shown in Fig. 2.

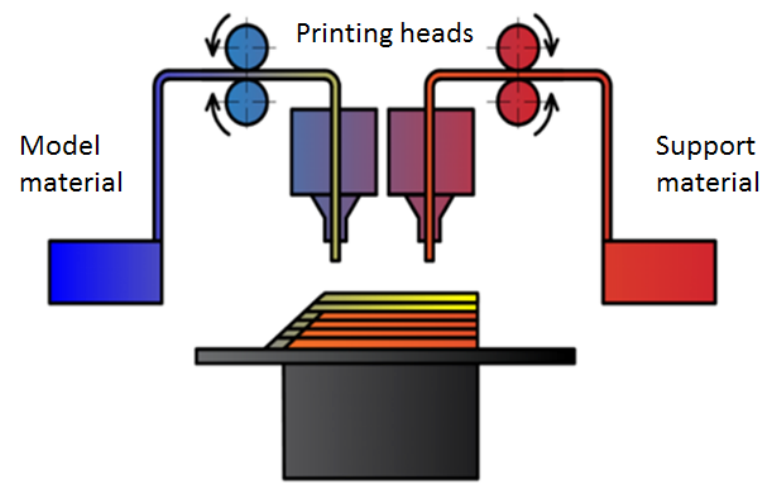

Fig. 1. FDM technology - concept

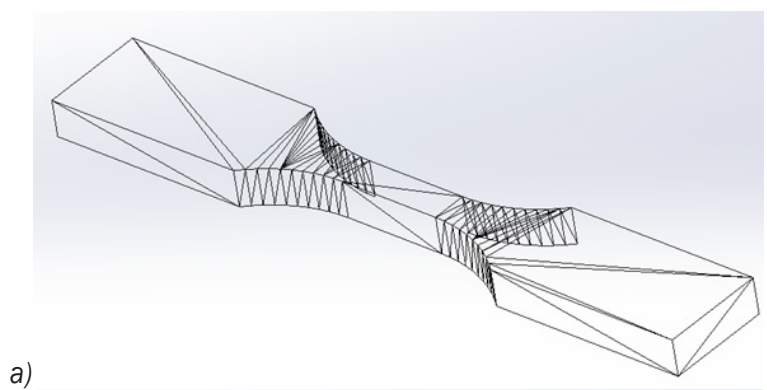

a)

b)

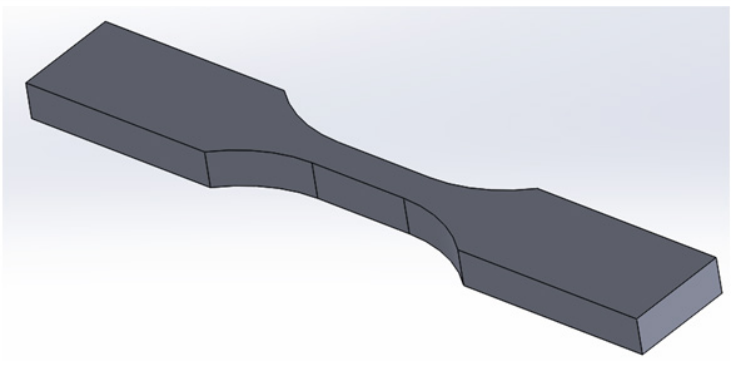

Fig. 2. Samples; a) STL file, and b) CAD model

For 3D printing, an Orcabot XXL (Prodim, The Netherlands) was used with PLA (Filamentworld, Neu-Ulm/Germany). The models were sliced with the included software Slic3r, applying the common $45^{\circ}$ raster angle. The printing parameters are given in Table 1. 
Table 1. Printing parameters

\begin{tabular}{lcc}
\hline Parameter & Value & Unit \\
\hline layer thickness & 0.2 & {$[\mathrm{~mm}]$} \\
\hline nozzle temperature & 210 & {$\left[{ }^{\circ} \mathrm{C}\right]$} \\
\hline building tray temperature & 60 & {$\left[{ }^{\circ} \mathrm{C}\right]$} \\
\hline infill material & 99.5 & {$[\%]$} \\
\hline
\end{tabular}

The first three samples (1 to 3) were not subjected to any finishing treatment. For some samples (4 to 18), heat treatment was carried out by heating in an oven at a heating rate of $1 \mathrm{~K} / \mathrm{min}$ to $60^{\circ} \mathrm{C}$ (samples 4 to 6), $80{ }^{\circ} \mathrm{C}$ (samples 7 to 9 ), $100{ }^{\circ} \mathrm{C}$ (samples 10 to 12), $120{ }^{\circ} \mathrm{C}$ (samples 13 to 15 ) or $140{ }^{\circ} \mathrm{C}$ (samples 16 to 18), respectively, followed by isothermal treatment at the final temperature for 60 minutes at the final temperature. In addition, chemical treatment of three samples (19 to 21) was carried out by exposing the models to acetone in the form of gas or immersion in the liquid for a period of $1 \mathrm{~min}, 2.5 \mathrm{~min}$ or $60 \mathrm{~min}$, respectively. Table 2 summarizes these treatments. In addition, tests were carried out on the samples and their finishing treatment in the form of an interaction with liquid acetone for a period of 3 hours, which, however, made the samples unsuitable for further tests (Fig. 3). It can be stated that a treatment longer than one hour is not recommended for samples exposed to liquid acetone.

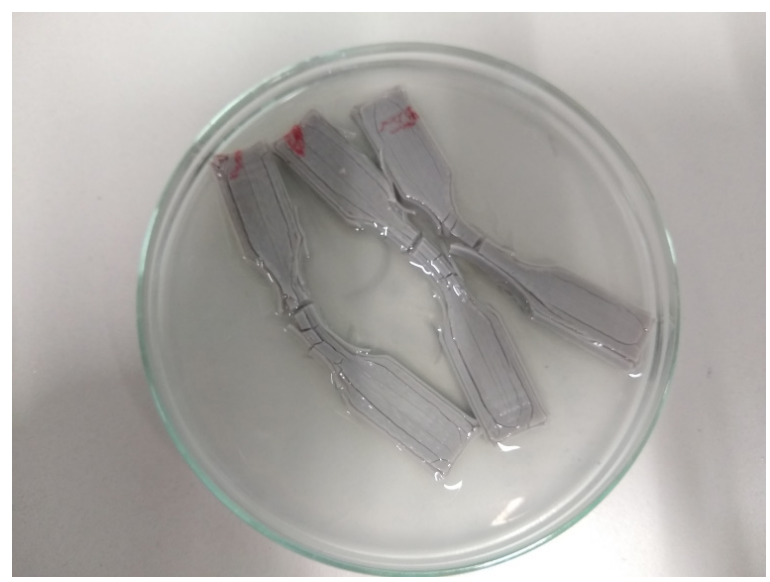

Fig. 3. Samples after 3 hours of liquid acetone treatment

Afterwards, the geometrical structure of the surface was evaluated. For this, all samples (1 to 21) were subjected to surface roughness and waviness measurements using a confocal laser scanning microscope (CLSM) VK-8710 (Keyence, Neu-Isenburg, Germany). The upper surface was investigated since the lower one generally shows strongly reduced waviness due to being solidified on the flat printing bed.
Table 2. Thermal and chemical treatments of samples

\begin{tabular}{lc}
\hline Sample no. & Treatment \\
\hline 1 to 3 & None \\
\hline 4 to 6 & Thermal at $60^{\circ} \mathrm{C}$ \\
\hline 7 to 9 & Thermal at $80^{\circ} \mathrm{C}$ \\
\hline 10 to 12 & Thermal at $100^{\circ} \mathrm{C}$ \\
\hline 13 to 15 & Thermal at $120^{\circ} \mathrm{C}$ \\
\hline 16 to 18 & Thermal at $140{ }^{\circ} \mathrm{C}$ \\
\hline $19 f / 19 \mathrm{~g}$ & Acetone 1 min (fluid / gaseous) \\
\hline $20 f / 20 \mathrm{~g}$ & Acetone 2.5 min (fluid / gaseous) \\
\hline $21 \mathrm{f} / 21 \mathrm{~g}$ & Acetone 60 min (fluid / gaseous) \\
\hline
\end{tabular}

An Excalibur 3100 (Varian, Inc., USA) was used for Fourier transform infrared (FTIR) spectroscopy.

The final stage of the study was to measure tensile strength for all 21 specimens (18 after treatment and 3 directly after printing) with an Inspekt mini $3 \mathrm{kN}$, measuring the tensile stress at break.

\section{RESULTS AND DISCUSSION}

The results of metrological and tensile strength measurements are presented in Figures 4 to 10, respectively.

The roughness values given here are defined as follows: $R a$ is the arithmetic mean deviation of the measured profile from the centreline of the evaluation length; $R q$ is the root mean squared of these deviations, and $R z$ is the average distance between the highest peak and lowest valley in each sampling area. The waviness values are defined in the same way, but with different "wavelengths", as indicated in each figure caption; roughness values indicate changes on smaller length scales (with an upper cutting wavelength of $0.08 \mathrm{~mm}$, i.e. $1 / 5$ of the width of one printed line, to exclude the waviness of the neighbouring printed lines) than waviness values (with a typical lower cutting wavelength of $2.5 \mu \mathrm{m}$, thus giving rise to the alternating hills and valleys of the neighbouring printed lines). Generally, here we use an optical measurement system and thus always give areal roughness/waviness values instead of line values, as they would be measured with a mechanical profilometer, to enable averaging over the whole surface instead of a randomly chosen line on this surface.

Fig. 4 depicts the roughness parameters $R z, R a$, and $R q$ for untreated and thermally treated samples. In all three parameters, no significant change due to temperature treatment is visible, while a slight tendency towards smaller values of $R a$ and $R q$ is visible for higher temperatures. 


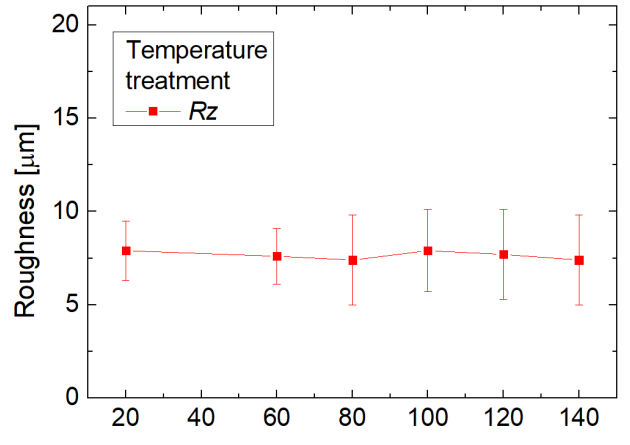

a)

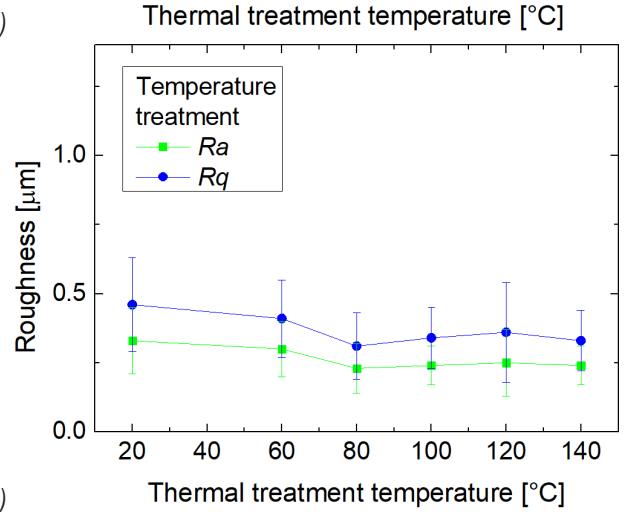

Fig. 4. Roughness surface parameters for heat-treated samples;

a) $R z$, and b) $R a$ and $R q$
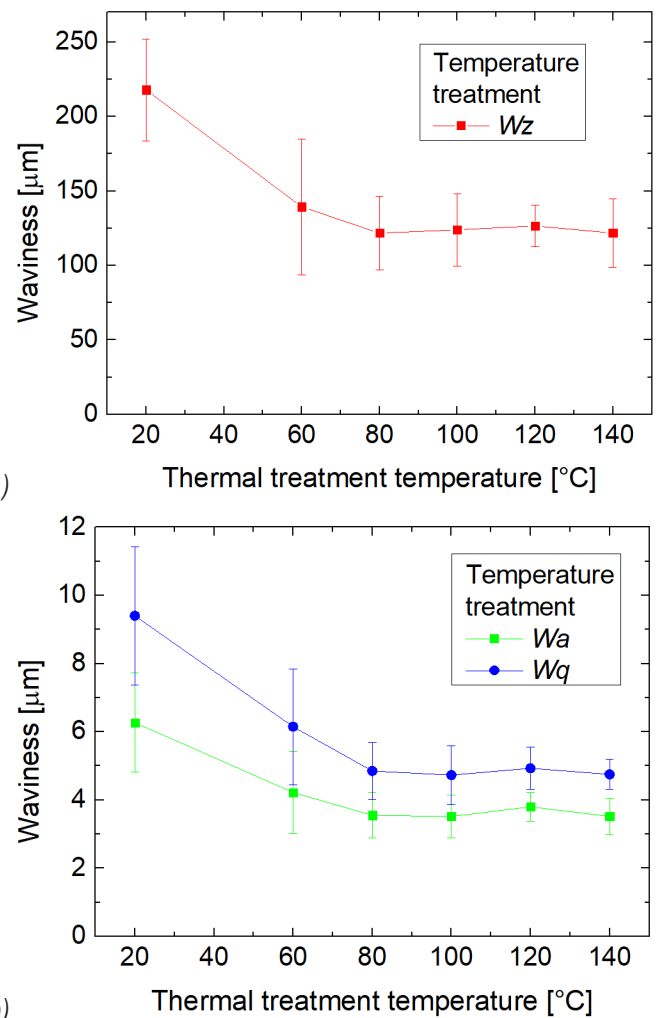

Fig. 5. Waviness surface parameters for heat-treated samples; a) Wz, and b) Wa and Wq
This is different for the waviness parameters depicted in Fig. 5. Here a clear difference between the untreated samples and the ones thermally treated at temperatures of $80^{\circ} \mathrm{C}$ or higher is visible, with all three waviness values $W z, W a$, and $W q$ decreasing significantly to approximately half of the original value.

Comparing Figs. 4 and 5 shows that temperature treatment indeed has an influence on the surface of FDM printed objects from PLA, although only the macro-scale (the waviness) is modified, while the micro-scale (the roughness) stays unaltered.

Next, the influence of an acetone treatment was investigated. Fig. 6 depicts the roughness values $R z, R a$ and $R q$ of untreated samples in comparison with acetone treatment in gaseous form. While no significant changes are visible for the shorter exposition durations, an increase of the roughness for the longest treatment is visible, which is nevertheless not significant. However, these measurement results fit well to the observation that the surface of these samples seems to be slightly less shiny than before the treatment.
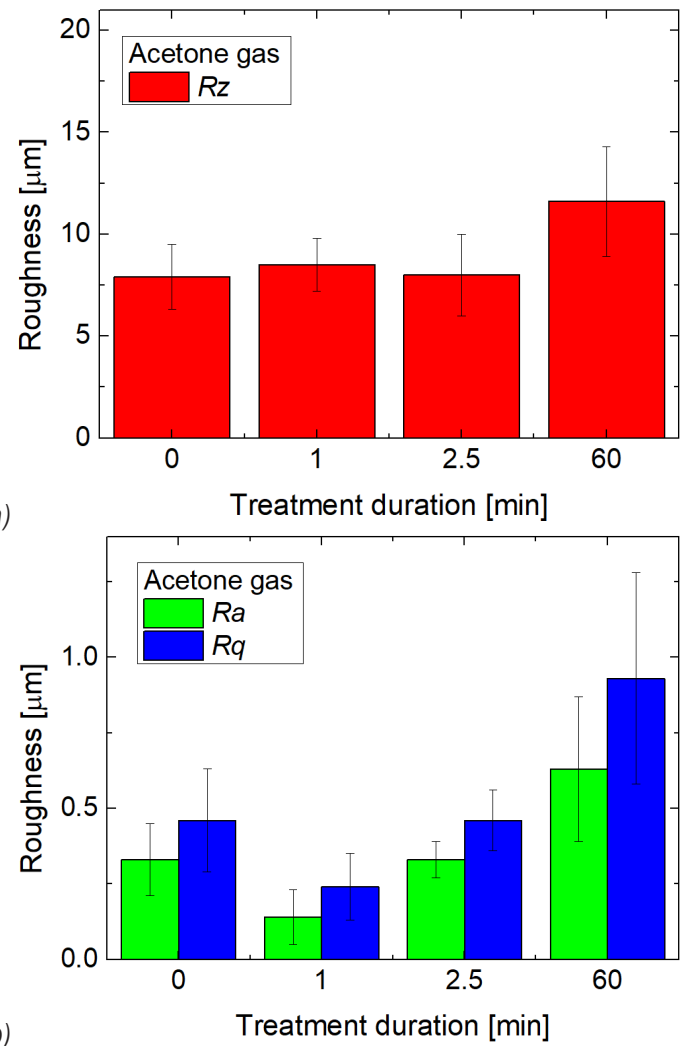

Fig. 6. Roughness surface parameters for acetone-treated samples (gas); a) $R z$, and b) $R a$ and $R q$ 


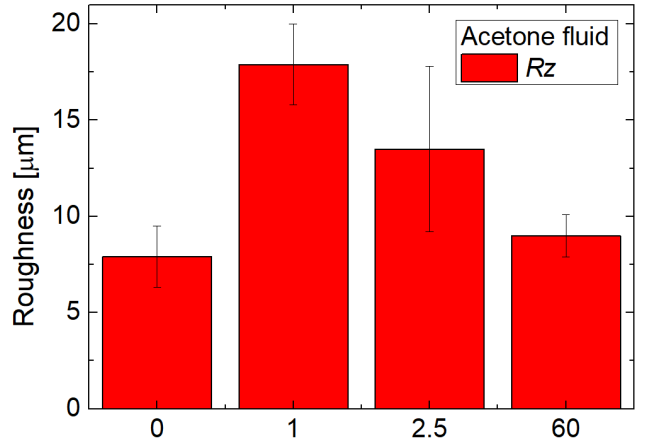

a)

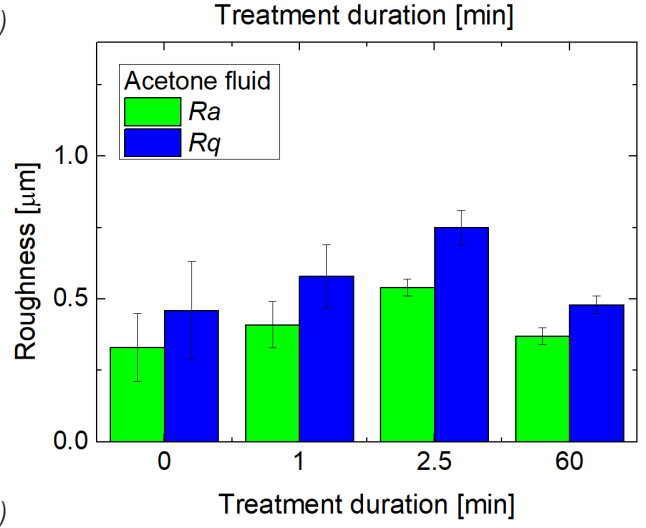

Fig. 7. Roughness surface parameters for acetone-treated samples (liquid); a) $R z$, and b) $R a$ and $R q$

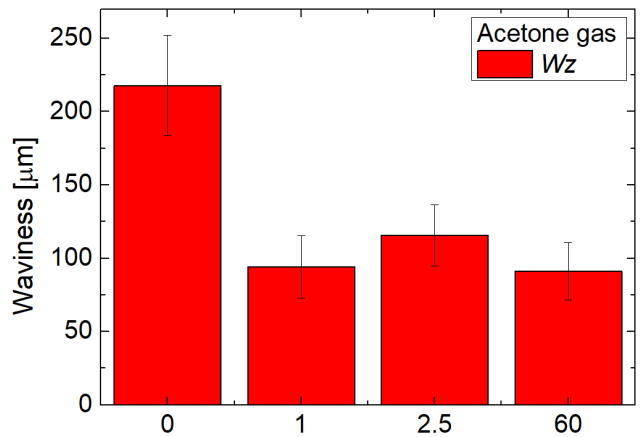

a)

Treatment duration [min]

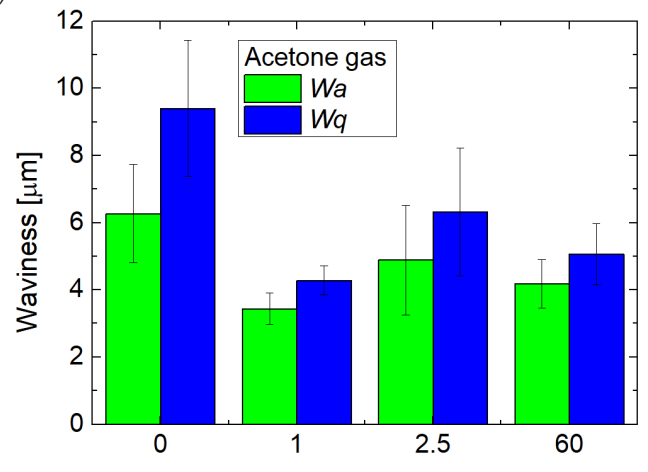

b)

Treatment duration [min]

Fig. 8. Waviness surface parameters for acetone treated samples (gas); a) Wz, an b) Wa and Wq
The impact of treatment with fluid acetone on the surface roughness is shown in Fig. 7. Interestingly, here even the shortest time shows a significant change of $R z$, while the other values remain similar. Is should be mentioned that after a treatment duration of 60 min, the original value of the untreated specimen is approached again.

While the treatment with acetone in fluid or gaseous form was disadvantageous - or in the best case neutral - in terms of surface roughness, Figs. 8 and 9 show that especially $W z$ is significantly reduced by an acetone treatment, while the other two waviness values are slightly reduced. This finding underlines that on larger scales, the surface gets more even, while the shine is reduced if the surface is not polished. Apparently, the planned application decides whether an acetone treatment makes sense as an aftertreatment, or whether it is counterproductive.

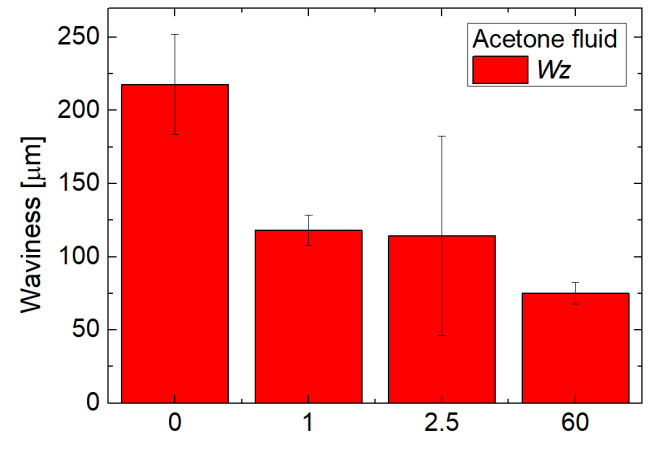

a)

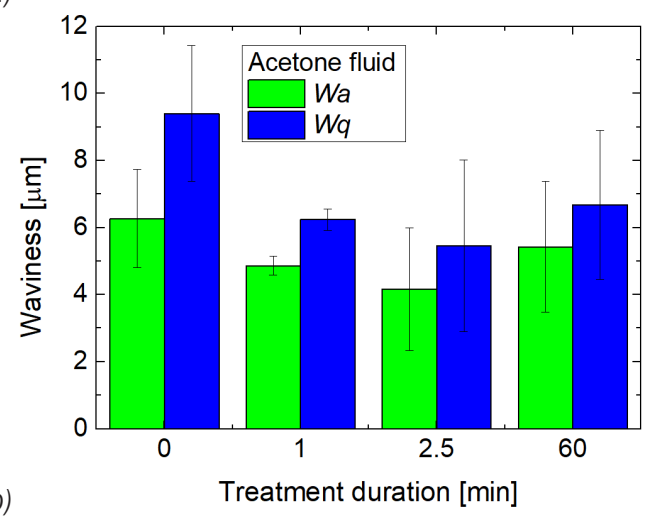

Fig. 9. Waviness surface parameters for acetone treated samples (liquid); a) Wz, an b) Wa and Wq

Generally, quantitatively analysing the results of metrological measurements, it can be stated that the thermal and chemical treatment with acetone has a slight effect on surface roughness parameters; however, the influence of treatments on the surface waviness of samples is clearly noticeable. The surface 
texture parameters measured after these treatments are concluded in Table 3.

Table 3. Surface texture parameters in [ $\mu \mathrm{m}]$

\begin{tabular}{ccccccc}
\hline No. & $R a$ & $R z$ & $R q$ & $W a$ & $W z$ & $W q$ \\
\hline 1 & 0.42 & 8.8 & 0.59 & 6.9 & 240 & 10.5 \\
\hline 2 & 0.27 & 8.0 & 0.38 & 6.4 & 215 & 9.5 \\
\hline 3 & 0.28 & 6.6 & 0.37 & 5.5 & 199 & 8.3 \\
\hline 4 & 0.29 & 8.0 & 0.40 & 3.9 & 120 & 5.5 \\
\hline 5 & 0.20 & 6.3 & 0.29 & 3.4 & 103 & 5.0 \\
\hline 6 & 0.40 & 7.9 & 0.56 & 5.4 & 194 & 8.0 \\
\hline 7 & 0.24 & 7.3 & 0.32 & 3.6 & 132 & 5.1 \\
\hline 8 & 0.28 & 8.9 & 0.40 & 3.9 & 126 & 5.4 \\
\hline 9 & 0.16 & 5.9 & 0.23 & 3.2 & 107 & 4.1 \\
\hline 10 & 0.20 & 7.5 & 0.27 & 3.4 & 114 & 4.5 \\
\hline 11 & 0.20 & 7.8 & 0.28 & 3.8 & 127 & 5.3 \\
\hline 12 & 0.31 & 8.4 & 0.46 & 3.4 & 131 & 4.4 \\
\hline 13 & 0.31 & 7.0 & 0.45 & 3.2 & 128 & 4.3 \\
\hline 14 & 0.17 & 7.9 & 0.25 & 4.2 & 128 & 5.6 \\
\hline 15 & 0.27 & 8.1 & 0.38 & 3.7 & 123 & 4.6 \\
\hline 16 & 0.27 & 7.0 & 0.38 & 3.2 & 133 & 4.1 \\
\hline 17 & 0.27 & 7.4 & 0.38 & 3.1 & 134 & 4.2 \\
\hline 18 & 0.19 & 6.1 & 0.26 & 3.6 & 102 & 4.6 \\
\hline $19 \mathrm{~g}$ & 0.14 & 8.5 & 0.24 & 3.4 & 74 & 4.3 \\
\hline $20 \mathrm{~g}$ & 0.33 & 8.0 & 0.46 & 5.9 & 216 & 8.3 \\
\hline $21 \mathrm{~g}$ & 0.63 & 11.6 & 0.93 & 4.2 & 91 & 5.1 \\
\hline $19 \mathrm{f}$ & 0.41 & 17.9 & 0.58 & 4.9 & 118 & 6.2 \\
\hline $20 \mathrm{f}$ & 0.54 & 13.5 & 0.75 & 4.2 & 96 & 5.6 \\
\hline $21 \mathrm{f}$ & 0.37 & 9.0 & 0.48 & 5.4 & 75 & 6.7 \\
\hline & & & & & & \\
\hline 13 & \\
\hline
\end{tabular}

Table 4. Mechanical properties of samples: tensile strength $\mathrm{Rm}$ and elongation $A$

\begin{tabular}{|c|c|c|c|c|c|}
\hline No. & $R m[\mathrm{MPa}]$ & $A[\%]$ & No. & $R m[\mathrm{MPa}]$ & $A[\%]$ \\
\hline 1 & 35.532 & 10.594 & 12 & 45.734 & 6.952 \\
\hline 2 & 45.962 & 8.119 & 13 & 44.958 & 6.813 \\
\hline 3 & 45.177 & 6.916 & 14 & 46.411 & 6.742 \\
\hline 4 & 46.347 & 8.647 & 15 & 47.262 & 7.130 \\
\hline 5 & 44.381 & 8.184 & 16 & 39.265 & 5.704 \\
\hline 6 & 41.884 & 8.886 & 17 & 45.138 & 5.453 \\
\hline 7 & 39.381 & 8.298 & 18 & 48.035 & 6.599 \\
\hline 8 & 41.652 & 7.331 & $19 \mathrm{~g} / \mathrm{f}$ & 31.579 & 6.865 \\
\hline 9 & 47.019 & 8.004 & $20 \mathrm{~g} / \mathrm{f}$ & 25.68 & 4.937 \\
\hline 10 & 45.648 & 8.107 & $21 \mathrm{~g} / \mathrm{f}$ & 8.369 & 31.769 \\
\hline 11 & 43.147 & 6.836 & & & \\
\hline
\end{tabular}

Analysing the results of tensile strength measurements of all types of samples, as depicted in Table 4, it can be seen that in almost all cases there is no clear effect of heat and chemical treatment on the tensile strength of the samples and on elongation. The exception is the tensile strength of the sample that was acetone treated for a period of 60 minutes.
In most cases, the tensile strength ranges from 35 $\mathrm{MPa}$ to $48 \mathrm{MPa}$, and the elongation is approximately 3 $\mathrm{mm}(5 \%$ to $10 \%)$. Tensile strengths of approximately $40 \mathrm{MPa}$ to $50 \mathrm{MPa}$ are typically for PLA 3D printed with a nozzle diameter of $0.4 \mathrm{~mm}$ and rectilinear infill. The maximum values of approximately $50 \mathrm{MPa}$ are given by the tensile strength of the pure filament, which is in the same range, while small deviations from a perfect printer setup lead to air holes in the specimens and thus to reduced tensile strength [23]. For sample 21 (acetone $60 \mathrm{~min}$ ), however, the tensile strength is much lower $(8.369 \mathrm{MPa})$, however, the elongation is almost $12 \mathrm{~mm}(31.769 \%)$. This is interesting because acetone treatment has positively influenced the waviness parameters. The increased elongation of sample 21 means that acetone treatment allows changing the physicochemical properties of samples and increasing the flexibility of the produced models, which in justified cases is a beneficial phenomenon, despite the lower tensile strength.

This is also visible in Fig. 10, showing the clear difference between sample 21 (lilac curve) and all other curves. Obviously, this sample is severely elongated, while the other samples, including Sample 1 , which breaks at an elongation of $4 \mathrm{~mm}$, show a brittle break.

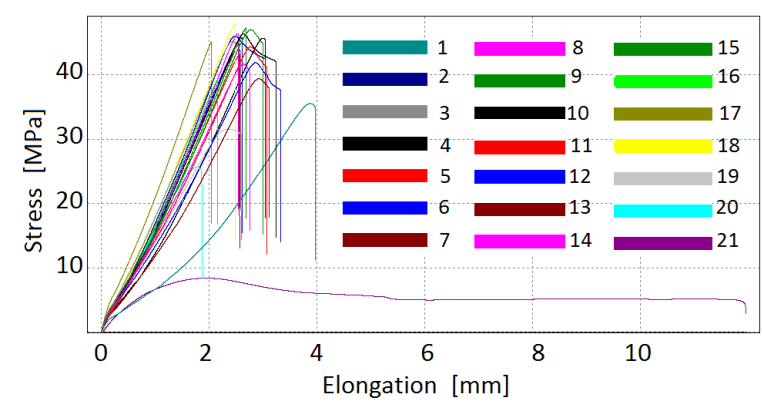

Fig. 10. Stress-strain curves of all samples under investigation in this study

To investigate the reason for this difference, FTIR measurements on the samples with and without aftertreatment were performed, which are depicted in Fig. 11.

In all cases, we see the typical peaks of the PLA backbone ester group, i.e., $1748 \mathrm{~cm}^{-1}$ ( $-\mathrm{C}=\mathrm{O}$ stretching), $1182 \mathrm{~cm}^{-1}(-\mathrm{C}-\mathrm{O}-\mathrm{C}$ stretching), $1133 \mathrm{~cm}^{-1}$ and $1079 \mathrm{~cm}^{-1}$ (both $-\mathrm{C}-\mathrm{O}-$ stretching) (all marked by solid lines) [24]. Additional typical PLA peaks can be found at $1452 \mathrm{~cm}^{-1}$ ( $-\mathrm{CH}_{3}$ bending), $1268 \mathrm{~cm}^{-1} \quad(-\mathrm{C}=\mathrm{O}$ bending), 1038 $\mathrm{cm}^{-1}$ (-OH bending) as well as $872 \mathrm{~cm}^{-1}$ and 754 $\mathrm{cm}^{-1}(-\mathrm{C}-\mathrm{C}-$ stretching of amorphous and crystalline 


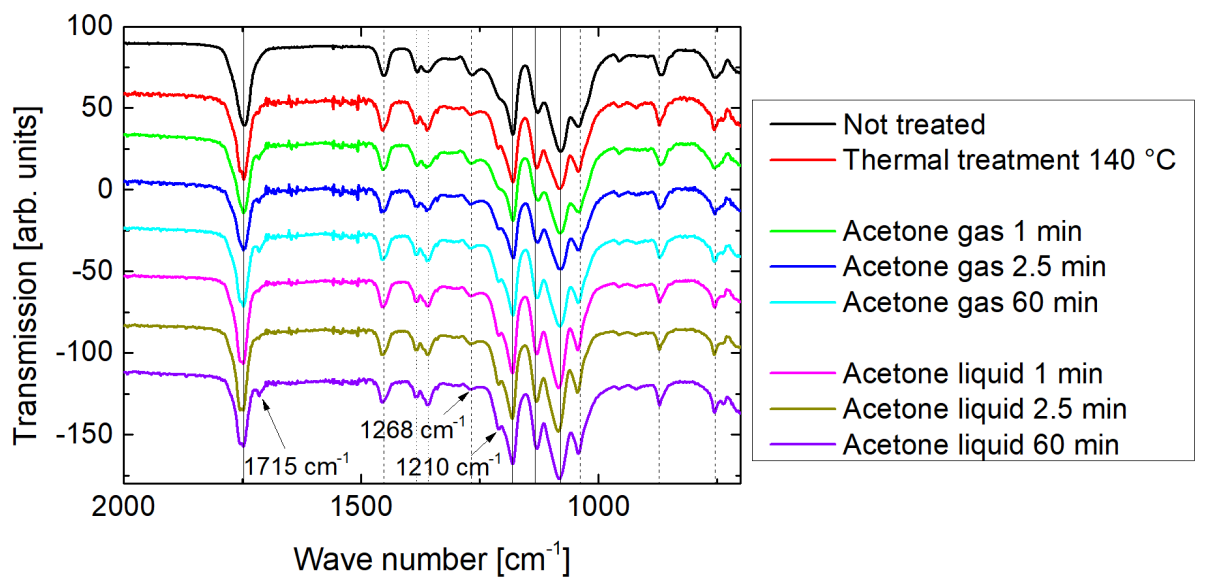

Fig. 11. FTIR measurements of untreated, thermally and acetone-treated specimens; the graphs are vertically offset for clarity

phases, respectively) (all marked by dashed lines) [25]. Finally, the small peaks around $1358 \mathrm{~cm}^{-1}$ and $1384 \mathrm{~cm}^{-1}$ can be attributed to $-\mathrm{CH}$ vibration and symmetric $-\mathrm{CH}_{3}$ bending, respectively (dotted lines) ([26] and [27]).

Differences between the untreated material and the material treated with liquid acetone for $60 \mathrm{~min}$ are not visible in the peaks at $872 \mathrm{~cm}^{-1}$ and $754 \mathrm{~cm}^{-1}$, indicating no change of the crystallinity near the surface where acetone-induced changes could be expected to be strongest [28].

Next, a possible modification of the molecular weight is investigated. An increase of the molecular weight by solvent treatment is indeed possible since low-molecular fractions may be dissolved, while higher-molecular fractions stay unaltered [29].

If the molecular weight is altered, changes should mostly be visible in the amount of end functional groups and ester bonds since low-molecular-weight PLA has more carboxylic acid and alcohol groups per mass than higher-molecular-weight PLA. On the other hand, higher-molecular weight PLA has more ester bonds due to enlarging the polymeric chain. This means that the peaks around $1748 \mathrm{~cm}^{-1}$ (carboxylic acid) should be higher for lower-molecular weight PLA, which is not the case for the acetone-treated samples. In [27] the high-molecular-weight PLA also shows an additional small peak around $1715 \mathrm{~cm}^{-1}$ on the shoulder of the large carboxylic acid peak, which is well visible here for most acetone treated specimens, especially for a duration of 60 min (marked by an arrow). These findings might indicate an increase in the molecular weight due to an acetone treatment.

On the other hand, the peak at $1268 \mathrm{~cm}^{-1}$ is significantly higher in our measurement of the original PLA, while it nearly vanishes for the acetone-treated specimens. Vanishing of this carbonyl ester group shows a reduced amount of these ester links, i.e. a lower molecular weight. Similarly, the peak at $1210 \mathrm{~cm}^{-1}$ - indicating the -OC-O stretching of carboxylic groups - is much more pronounced for the acetone-treated samples than for the original one, which is again a sign of a lower molecular weight.

Since these findings are inconsistent, a possible modification of the molecular weight due to the acetone treatment cannot be verified or falsified by the FTIR measurements.

Generally, it can be assumed that treating the specimens with a solvent partly destroys the molecular structure of PLA and thus weakens the molecular chain interaction [30], changing the original brittle behaviour into a more ductile one.

\section{CONCLUSIONS}

After an analysis of the presented research results, the following general conclusions can be formulated:

The geometric structure of the surface after thermal and chemical treatment is different from that immediately after printing. It has been shown that this effect is insignificant with respect to roughness parameters; however, it is clearly visible in the case of surface waviness parameters, which in many cases are incorrectly ignored.

Tensile strength when using thermal treatment did not change significantly; however, in the case of chemical treatment with acetone, a noticeable decrease in strength intensified by the elongation of the acetone effect can be seen. At the same time, a large increase 
in elongation was observed, especially for samples subjected to 60 minutes of acetone treatment, which is a positive phenomenon in many applications. Tests also showed that the interaction with liquid acetone for a duration longer than one hour causes the samples to break down with significant deformation.

The FTIR measurements are inconsistent; a possible modification of the average molecular weight due to the acetone treatment cannot be verified or falsified and should be investigated in a follow-up study using much longer solvent treatment durations.

\section{ACKNOWLEDGEMENTS}

This research was funded by the DAAD, funding program number 57440917 - Research Grant. The APC is funded by the Open Access Publication Fund of Bielefeld University of Applied Sciences and the Deutsche Forschungsgemeinschaft (DFG, German Research Foundation) - 414001623.

\section{REFERENCES}

[1] Chua, C.K., Leong, K.F., Lim, C.S. (2003). Rapid Prototyping: Principles and Applications, $2^{\text {nd }}$ Edition. World Scientific Publishing, Singapore.

[2] Novakova-Marcincinova, L. (2012). Application of fused deposition modeling technology in 3D printing rapid prototyping area. Manufacturing and Industrial Engineering, vol. 11, no. 4, p. 35-37.

[3] Noorani, R. (2005) Rapid Prototyping: Principles and Applications. John Wiley \& Sons, New Jersey.

[4] Ben-Ner, A., Siemsen, E. (2017). Decentralization and localization of production: the organizational and economic consequences of additive manufacturing (3D printing). California Management Review, vol. 59, no. 2, p. 5-23, DOI:10.1177/0008125617695284.

[5] Kousiatza, C., Tzatzis, D., Karalekas, D. (2019). In-situ characterization of $3 D$ printed continuous fiber reinforced composites: A methodological study using fiber Bragg grating sensors. Composites Science and Technology, vol. 174, p. 134-141, D0l:10.1016/j.compscitech.2019.02.008.

[6] Li, Q.S., Zhao, W., Li, Y.W., Yang, W.W., Wang, G. (2019). Flexural Properties and Fracture Behavior of CF/PEEK in Orthogonal Building Orientation by FDM: Microstructure and Mechanism. Polymers, vol. 11, no. 4, p. 656, Dol:10.3390/ polym11040656.

[7] Kozior, T., Trabelsi, M., Mamun, A., Sabantina, L., Ehrmann, A. (2019). Stabilization of electrospun nanofiber mats used for filters by 3D printing. Polymers, vol. 11, no. 10, p. 1618, Dol:10.3390/polym11101618.

[8] Adamczak, S., Zmarzły, P., Kozior, T., Gogolewski, D. (2017). Analysis of the dimensional accuracy of casting models manufactured by fused deposition modeling technology. Engineering Mechanics 2017, 23rd International Conference, p. 66-69, D0l:10.2507/29th.daaam.proceedings.123.
[9] Rokicki, P., Budzik, G., Kubiak, K., Bernaczek, J., Dziubek, T., Magniszewski, M., Nowotnik, A., Sieniawski, J., Matysiak, H., Cygan, R., Trojan, A. (2014). Rapid prototyping in manufacturing of core models of aircraft engine blades. Aircraft Engineering and Aerospace Technology, vol. 86, no. 4, p. 323-327, D0I:10.1108/AEAT-10-2012-0192.

[10] ISO 10993-1:2010. Biological Evaluation of Medical Devices - Part 1: Evaluation and Testing within a Risk Management Process. International Standard Organization, Geneva.

[11] Kozior, T., Döpke, C., Grimmelsmann, N., Juhász Junger, I., Ehrmann, A. (2018). Influence of fabric pretreatment on adhesion of three-dimensional printed material on textile substrates. Advances in Mechanical Engineering, vol. 10, no. 8, Dol:10.1177/1687814018792316.

[12] Mamun, A., Trabelsi, M., Klöcker M., Sabantina, L., Großerhode, C., Blachowicz, T., Grötsch, G., Cornelißen, C., Streitenberger, A., Ehrmann, A. (2019). Electrospun nanofiber mats with embedded non-sintered $\mathrm{TiO}_{2}$ for dye-sensitized solar cells (DSSCs). Fibers, vol. 7, no. 7, p. 60, D0l:10.3390/ fib7070060.

[13] Kundera, Cz., Kozior, T. (2014). Research of the elastic properties of bellows made in SLS technology. Advanced Materials Research, vol. 874, p. 77-81, D0I:10.4028/www. scientific.net/AMR.874.77.

[14] Kundera, Cz., Martsynkowskyy, V., Gudkov, S., Kozior, T. (2017). Effect of rheological parameters of elastomeric ring materials on dynamic of face seals. Procedia Engineering, vol. 177, p. 307-313, D0I:10.1016/j.proeng.2017.02.230.

[15] Krolczyk, G., Raos, P., Legutko, S. (2014). Experimental analysis of surface roughness and surface texture of machined and fused deposition modeling parts. Tehnički Vjesnik - Technical Gazette, vol. 21, no. 1, p. 217-221.

[16] Kozior, T., Kundera, Cz., (2017). Evaluation of the influence of parameters of FDM technology on the selected mechanical properties of models. Procedia Engineering, vol. 192, p. 463468, D0I:10.1016/j.proeng.2017.06.080.

[17] Bochnia, J., Blasiak, S. (2018). Fractional relaxation model of materials obtained with selective laser sintering technology. Rapid Prototyping Journal, vol. 25, no. 1, p. 76-86, DOl:10.1108/RPJ-11-2017-0236.

[18] Garg, A., Bhattacharya, A., Batish, A. (2016). On surface finish and dimensional accuracy of FDM parts after cold vapor treatment. Materials and Manufacturing Processes, vol. 31, no. 4, p. 522-529, D0I:10.1080/10426914.2015.1070425.

[19] Rao, A.S., Dharap, M.A., Venkatesh, J.V.L., Ojha, D. (2012). Investigation of post processing techniques to reduce the surface roughness of fused deposition modeled parts. International Journal of Mechanical Engineering and Technology, vol. 3, no. 3, p. 531-544.

[20] Beniak, J., Križan, P., Šooš, L., Matúš, M. (2018). Roughness and compressive strength of FDM 3D printed specimens affected by acetone vapour treatment. IOP Conference Series: Materials Science and Engineering, vol. 297, DOI:10.1088/1757-899X/297/1/012018.

[21] Havenga, S.P., de Beer, D.J., van Tonder, P.J., Campbell, R.I. (2018). The effect of acetone as a post-production finishing technique on entry-level material extrusion part quality. The 
South African Journal of Industrial Engineering, vol. 29, no. 4, DOl:10.7166/29-4-1934.

[22] Wach, R.A., Wolszczak, P., Adamus-Włodarczyk, A. (2018). Enhancement of mechanical properties of FDM-PLA parts via thermal annealing. Macromolecular Materials and Engineering, vol. 303, no. 9, Dol:10.1002/mame.201800169.

[23] Fafenrot, S., Grimmelsmann, N., Wortmann, M., Ehrmann, A. (2017) Three-dimensional (3D) printing of polymer-metal hybrid materials by fused deposition modeling. Materials, vol. 10, no. 10, p. 1199, Dol:10.3390/ma10101199.

[24] Suarez-Franco, J.L., Vázquez-Vázquez, F.C., Pozoz-Guillen, A., Montesinos, J.J., Alvarez-Fregoso, 0., Alvarez-Perez, M.A. (2018). Influence of diameter of fiber membrane scaffolds on the biocompatibility of hPDL mesenchymal stromal cells. Dental Materials Journal, vol. 37, no. 3, p. 465-473, D0l:10.4012/dmj.2016-329.

[25] Rocca-Smith, J.R., Lagorce-Tachon, A., laconelli, C., Bellat, J.P., Marcuzzo, E., Sensidoni, A., Piasente, F., Debeaufort, F., Karbowiak, T. (2017). How high pressure $\mathrm{CO}_{2}$ impacts PLA film properties. Express Polymer Letters, vol. 11, no. 4, p. 320333, D0I:10.3144/expresspolymlett.2017.31.

[26] Silva Murakami, L.M., Baracho Azevedo, J., Diniz, M.F., Silva, L.M., de Cássia Lazzarini Dutra, R. (2018). Characterization of additives in NR formulations by TLC-IR (UATR). Polímeros, vol. 28, no. 3, p. 205-214, DOl:10.1590/0104-1428.06317.
[27] Palacio, J., Orozco, V.H., López, B.L. (2011). Effect of the molecular weight on the physicochemical properties of poy(lactic acid) nanoparticles and on the amount of ovalbumin adsorption. Journal of the Brazilian Chemical Society, vol. 22, no. 12, p. 2304-2311, D0l:10.1590/S010350532011001200010.

[28] Goncalves, C.M.B., Coutinho, J.A.P., Marrucho, I.M. (2010). Optical Properties. Poly(lactic acid): Synthesis, Structures, Properties, Processing, and Applications. Auras, R.; Lim, L.-T.; Selke, S.E.M.; Tsuji, H. (eds.), John Wiley \& Sons, Hoboken, p. 97-112, D0l:10.1002/9780470649848.ch8.

[29] Renbenberger, R., Cayla, A., Villmow, T., Jehnichen, D., Campagne, C., Rochery, M., Devaux, E., Pötschke, P. (2011). Multifilament fibres of poly( $\varepsilon$-caprolactone)/poly(lactic acid) blends with multiwalled carbon nanotubes as sensor materials for ethyl acetate and acetone. Sensors and Actuators B: Chemical, vol. 160, no. 1, p. 22-31, D0l:10.1016/j. snb.2011.07.004.

[30] Jin, Y.F., Wan, Y., Zhang, B., Liu, Z.Q. (2017). Modeling of the chemical finishing process for polylactic acid parts in fused deposition modeling and investigation of its tensile properties. Journal of Materials Processing Technology, vol. 240, p. 233239, D0I:10.1016/j.jmatprotec.2016.10.003. 